\title{
DE NUEVO SOBRE LA «GUERRA DEL ESTRECHO»: LA CONTRIBUCIÓN FINANCIERA DEL REINO DE VALENCIA EN LA ÚLTIMA FASE DEL CONFLICTO (1332-1344)
}

\author{
María Dolores LÓPEZ \\ Universidad de Barcelona
}

La lucha por el Estrecho, en la que se vieron involucrados los mariníes, el reino de Granada y Castilla, así como la Corona de Aragón, Portugal y Génova, se circunscribe en un período cronológico que abarca desde 1275 hasta 1344 y se caracteriza por un complejo y cambiante sistema de alianzas entre las diferentes potencias implicadas en el conflicto. El control de las principales plazas situadas en el estrecho, Algeciras, Gibraltar, Tarifa o Ronda, en la península, o Ceuta en el espacio norteafricano, y con ellas las comunicaciones Mediterráneo-Atlántico, se encuentra en la base de un conflicto cuyo desarrollo es bastante bien conocido. La historiografía se ha ocupado ampliamente, aunque de manera desigual, de los acontecimientos bélicos así como de las consecuencias políticas y económicas derivadas de la intervención mariní en la península, si bien la última intervención es la que ha atraído el interés mayoritario de los historiadores'.

La última fase tuvo lugar entre 1332 y 1344 y se vio propiciada por el reforzamiento del poder mariní en la persona de Abu-l-Hasan tras un período de crisis sucesorias y disidencias internas. El tránsito de los siglos XIII al XIV fue un período de empuje castellano, secundado por el apoyo catalano-aragonés, frente a la impotencia evidente de los sultanes mariníes, determinados por los conflictos internos. La subida al poder

1 Una amplia referencia bibliográfica sobre esta cuestión puede verse en M.D. LÓPEZ PÉREZ, La Corona de Aragón y el Magreb en el siglos XIV (1331-1410), Barcelona: Institución Milá y Fontanals, 1995, p. 58. 
de Abu-l-Hasan en 1331 supondrá la reanudación de la expansión mariní de los territorios peninsulares.

La petición de ayuda elevada por el sultán nazarí Muhammad IV a Abu-I-Hasan, en 1332, ante el renovado empuje castellano en las zonas fronterizas, sería el detonante de esta última intervención que se materializó en la toma de Gibraltar. La firma de una tregua con Castilla y la Corona de Aragón, en 1334 y 1335, respectivamente, así como el interés preferente del sultán mariní en la expansión hacia el este magrebí, supusieron un intermedio en la lucha por el control del estrecho, una lucha que se reanudó tras la toma de Tremecén por los marroquíes en 1337.

Ante esta posible expansión territorial magrebí en la península, una expansión terrestre, favorecida por la alianza mariní-nazarí, y una expansión marítima posibilitada por la intensa actividad armadora desarrollada en las atarazanas marroquies, las diferentes potencias peninsulares no podían permanecer impasibles. No entraremos en el desarrollo de los acontecimientos ${ }^{2}$, pero sí es importante remarcar que, ante la gravedad de la situación Castilla y la Corona de Aragón firmaron un tratado de cooperación, el Tratado de Madrid, en 1339, con el objetivo de controlar el área marítima del sur peninsular ante las alarmantes noticias del paso de tropas marroquíes a la península. Según este acuerdo, Castilla debía contribuir a la vigilancia del estrecho con veinte galeras durante cinco meses, desde mayo a septiembre, y con ocho el resto del año, mientras que la corona de Aragón aportaría la mitad de embarcaciones, es decir, diez galeras en la temporada estival y cuatro desde octubre hasta abril. Este número podía aumentar o disminuir según las necesidades de un momento concreto, pero siempre en idéntica proporción $n^{3}$. Desde un punto de vista teórico, los acuerdos de colaboración catalano-aragonesa castellana en materia de defensa marítima aseguraban el mantenimiento de una escuadra compuesta de treinta galeras en los espacios temporales de alto riesgo y de doce durante el período invernal. La documentación posterior certifica, sin embargo, el incumplimiento de los términos estipulados por parte de la Corona de Aragón, pero también de Castilla. Cuestiones coyunturales inherentes a las dificultades de financiación, supeditada en gran medida a los donativos de Cortes, y el desvio de una parte de recursos monetarios hacia otras empresas bélicas, bastarían para explicar la imposibilidad de cumplir con los acuerdos pactados. Paralelamente, la evolución del conflicto desde una inicial e inminente invasión de la península hasta una situación claramente beneficiaria para la Corona de Castilla, a raíz de la derrota musulmana del Salado, en octubre de 1340, bastarían para justificar el paulatino desinterés de la Corona de Aragón más preocupada en la solución de sus propios conflictos internos que en la conquista castellana de la plaza de Algeciras. Con todo, Pedro

2 Analizados en M.D. LÓPEZ PÉREZ, La Corona de Aragón y el Magreb, pp. 55-96.

3 Las cláusulas de este tratado son bien conocidas al haber sido publicadas por P. de Bofarull en su recopilación de documentos del Archivo de la Corona de Aragón [Codoin, VII, doc. 5, pp. 87-96] y por las referencias incluidas en la obra de J. Zurita [Anales de la Corona de Aragón, Zaragoza: Consejo Superior de Investigaciones Científicas, 1973, vols. III, p. 471]. Sobre este acuerdo: M.D. LÓPEZ PÉREZ, La Corona de Aragón y el Magreb, pp. 72-83. 
el Ceremonioso intentará mantener una colaboración de compromiso hasta la finalización definitiva de la cuestión del Estrecho.

Cumplir los compromisos implicaba un fuerte desembolso monetario. La organización de una escuadra de diez galeras durante el período estival y cuatro los restantes meses del año, precisaba de importantes sumas de capital y de un fuerte desembolso inicial, especialmente si no se disponía de un número suficiente y era preciso construir algunos navíos. Los salarios de la tripulación y una adecuada provisión de víveres que garantizara la manutención durante la travesía constituían, asimismo, algunas de las partidas de gastos más importantes; unos gastos que se completaban con el armamento en armas ofensivas y defensivas, tanto de la propia embarcación como de los hombres que la tripulaban, así como el equipamiento de velas, mástiles, timones y entenas. Los mecanismos de financiación utilizados por Pedro el Ceremonioso no difieren sustancialmente de los sistemas habituales empleados por la monarquía catalano-aragonesa del trescientos para financiar sus empresas militares. Los recursos del patrimonio real resultaban cada vez más insuficientes dadas las crecientes necesidades del estado. Las continuas y repetidas alienaciones de las rentas reales efectuadas por los sucesivos monarcas ya desde el siglo XIII y a lo largo del trescientos estuvieron motivadas, sobre todo, por la apertura de sucesivos frentes de guerra y el consiguiente aumento de los gastos bélicos, consecuencia de la política expansionista llevada a cabo por la Corona ${ }^{4}$.

La cuestión marroquí, a la que se superpuso la recuperación para la Corona de los dominios del rey de Mallorca, puso de manifiesto la inviabilidad del monarca de disponer de las cantidades suficientes para cumplir con los compromisos contraídos en el Tratado de Madrid. Para una empresa de esta envergadura el monarca precisaba de una serie de recursos extraordinarios que debían ser otorgados por las Cortes. El grado de cooperación estaba lógicamente en relación directa con el grado de peligrosidad de un ataque del sultán mariní y la disponibilidad de Pedro el Ceremonioso a aceptar las prerrogativas exigidas por los diferentes estamentos a cambio de las subvenciones monetarias. El reino de Valencia, directamente afectado por una posible invasión, marítima y terrestre, del ejército mariní, mostró una pronta disposición a colaborar en la financiación de la flota. En agosto de 1339, la ciudad de Valencia, ante la petición de subsidios realizada por el rey, le otorga la cantidad de 100.000 sueldos $^{5}$.

4 Este proceso de desintegración del patrimonio real y los intentos de reincorporación efectuados a finales del trescientos por Martín el Humano han sido estudiados magistralmente por M.T. FERRER en su artículo «El patrimoni reial i la recuperació dels senyorius jurisdiccionals en els estats catalanoaragonesos a la fi del segle XIV», Anuario de Estudios Medievales 7 (1970-1971), pp. 351-491.

5 M. SÁNCHEZ y S. GASSIOT, «La Cort General de Barcelona (1340) y la contribución catalana a la guerra del Estrecho», Les Corts a Catalunya. Actes del Congrès d'Història Institucional, (Barcelona, 1988), Barcelona: Generalitat de Catalunya, 1991, p. 225. De estos 100.000 sueldos deberían descontarse 22.314 sueldos, 4 dineros adelantados por los jurados al almirante Jofre Gilabert de Cruïlles, quien se encontraba en el Estrecho desde el mes de julio con el primer reemplazo de galeras enviado por la Corona de Aragón. Los restantes 77.685 sueldos, 8 dineros, necesarios para el pago de salarios de las tripulaciones, se obtuvieron a través de la venta por dos años de la imposición sobre las 
El pago efectuado por la universidad valenciana permitió al monarca cubrir una parte de los gastos derivados de la permanencia de la flota en los mares de Tarifa desde julio hasta finales de septiembre de 1339 , si bien a partir de esas fechas, las galeras que continuaron con las labores de vigilancia lo hicieron a cargo económico del rey castellano ${ }^{6}$.

El sostenimiento de un número regular de navíos en el área marítima sur peninsular precisaba de elevadas cantidades que el monarca catalano-aragonés únicamente podía conseguir a través de donativos pactados en las Cortes. La carencia de embarcaciones catalano-aragonesas en el Estrecho durante todo un año, desde octubre de 1339 hasta octubre de 1340 , se explicaría, en parte, por una falta de disponibilidad de recursos susceptibles de ser invertidos en el armamento de naves destinadas a la guerra de Marruecos. La victoria de la escuadra musulmana sobre la flota castellana, reforzada por las cuatro galeras catalano-aragonesas al mando de Dalmau de Cruïlles, en abril de 1340 sería el desencadenante para proceder a una rápida convocatoria de Cortes, primero en Valencia y más tarde en Cataluña.

Inmediatamente después de conocerse en la corte las noticias de la derrota, Pedro el Ceremonioso procedía a convocar Cortes en la ciudad de Valencia para mediados del mes de mayo ${ }^{7}$. Los capítulos refrendados por los diferentes estamentos repre-

carnes. Las imposiciones, dado su carácter de contribuciones irregulares instituidas en momentos de necesidades extraordinarias de numerario, debían ser aprobadas por el rey, aunque las universidades gozaban de una total autonomía respecto a las modalidades de recaudación de los impuestos. La propia universidad decidía cuáles debían ser los productos gravados y las tasas a imponer, siempre en relación directa con las necesidades monetarias de ese momento concreto, mientras que el monarca únicamente refrendaba y otorgaba los capítulos de las imposiciones. Así, los emisarios enviados por el rey ante los jurados de Valencia en agosto de 1339 con motivo de la concesión de un subsidio especial, Berenguer de Codinacs y Bernat de Ripoll, tenían suficientes prerrogativas para conceder a la universidad, una vez otorgado el subsidio, plenos poderes con el objeto de crear una imposición sobre aquellos productos que consideraran susceptibles de un mayor rendimiento [Archivo de la Corona de Aragón (en adelante ACA), Cancillería (en adelante C), reg. 1377, f. 28 v. (Barcelona. 29, junio, 1339)]. En las deliberaciones del consejo, sobre los diferentes mecanismos posibles para obtener esa cantidad en el tiempo concertado para el pago, se consideró la posibilidad, junto con la venta de la imposición sobre las carnes, de recurrir a la questia o manleuta. Finalmente se optó por la primera alternativa, siempre teniendo en cuenta que la imposición, que había sido otorgada por el rey con una duración de seis años, había sido ya vendida en sus $2 / 3$ partes, es decir, por cuatro años [Archivo Municipal de Valencia (en adelante AMV), Manuals de Consells, A-3, ff. 299 r.-v. (Valencia. 25, agosto, 1339)]. El comprador de los dos años restantes, por una suma total de 80.000 sueldos, fue Bernat Joan, cambiador y jurado de la ciudad, según se acordó en el consejo de la universidad celebrado el 1 de septiembre de 1339 [AMV, Manuals de Consells, A-3, ff. 300 r.-301 v. (Valencia. 1, septiembre, 1339)].

6 Sobre la flota catalano-aragonesa en el estrecho cf. M.D. LÓPEZ PÉREZ, La Corona de Aragón y el Magreb, pp. 72-83.

7 En las cartas dirigidas a los jurados y prohombres de diferentes villas reales del reino de Valencia (Morella, Villareal, Castelló de Burriana, Morvedre, Alzira, Játiva, Jijona, Liria, Cullera y Corbera), el monarca les notifica que, ante las noticias de la pérdida de galeras en el conflicto con el soberano mariní, había decretado la obligatoriedad de todos sus súbditos de prestar la ayuda necesaria. Por 
sentados establecen, en primer lugar, la concesión de un subsidio o almoina, con una duración de 3 años, destinado a la defensa marítima, cuya cuantía debería ser suficiente para mantener veinte galeras durante un período de cuatro meses y otras cinco los ocho meses restantes ${ }^{8}$.

Para obtener las cantidades necesarias se procedió a promulgar unas imposiciones, generales en todo el reino de Valencia, sobre las transacciones efectuadas con toda una serie de productos, alimentarios y manufacturados; una imposición que gravaba, básicamente, tanto la compra como la venta. Asimismo, se impuso una tasa, en el caso de las villas marítimas, sobre la entrada y salida de embarcaciones de sus puertos. Si bien estas ordenaciones tienen un carácter general, los capítulos contemplan la posibilidad de una reducción de las tasas, nunca un aumento, dependiendo de la situación concreta de las diferentes universidades donde se levaban las imposiciones. La tipología de los productos sujetos al pago de gravámenes, así como la imposición de derechos sobre el tráfico mercantil nos hace pensar que en su elaboración se tomó como modelo la propia ciudad de Valencia, e incluso posibles imposiciones decretadas con anterioridad por esta universidad ${ }^{9}$. En consecuencia, se trataria de un modelo de base, susceptible de adaptarse a las diferentes condiciones económicas y sociales de cada uno de los lugares obligados al pago del subsidio.

En relación al valor de las tarifas, observamos, en primer lugar, que las tasas impuestas sobre los cereales varían notablemente en relación a la calidad de los granos. El trigo candeal paga a razón de 2 sueldos por cahíz, mientras que el resto — panizo, maíz, cebada, avena y centeno- abonan justamente la mitad: 12 dineros. Es importante remarcar que la compra de cereales destinados a uso mercantil o para la siembra no pagaba ningún tipo de tasa.

Las carnes, frescas y saladas, son objeto de una amplia reglamentación a nivel de

este motivo requería la presencia de sus representantes en la ciudad de Valencia con los poderes y facultades suficientes para conceder subsidios [ACA, C, reg. 1377, f. 44 r.-v. (Zaragoza. 1, mayo, 1340); M. SÁNCHEZ y S. GASSIOT, La Cort General de Barcelona (1340), p. 226]. Sobre estas Cortes cf. J. MARTÍNEZ ALOY, La Diputación de la Generalidad del reino de Valencia, Valencia, 1930; M. DUALDE, Solidaridad espiritual de Valencia con las victorias cristianas del Salado y Algeciras, Valencia: Instituto Valenciano de Estudios Históricos-Institución Alfonso el Magnánimo, 1950; M.R. MUÑOZ, Orígenes de la Generalidad valenciana, Valencia: Generalitat valenciana, 1987, pp. 47-52. Véase asimismo, de esta última autora, "Las Cortes de 1339, paso previo en la alianza contra los benimerines", Estudios dedicados a Juan Peset Aleixandre, Valencia: Universidad de Valencia, 1982, III, pp. 51-64.

8 Los capítulos aprobados en las Cortes valencianas de 1340, con fecha del 2 de junio, referentes a la concesión del subsidio se conservan en el registro 1377, de la sección de Cancillería del Archivo de la Corona de Aragón, folios 54 v.-63 r. cit. M. SÁNCHEZ y S. GASSIOT, La Cort General de Barcelona (1340), pp. 226 y 235.

9 Por ejemplo, en las Cortes de Valencia de 1329-1330 se decretó la imposición de tasas sobre determinados productos para la obtención de la cantidad ofrecida por los estamentos a Alfonso el Benigno; una cantidad otorgada en ayuda a la Cruzada pactada con Alfonso XI de Castilla contra el sultán de Granada. Un estudio sobre esta cuestión puede verse en M. SÁNCHEZ, "La contribución valenciana a la Cruzada granadina de Alfonso IV de Aragón (1327-1336)", Primer Congreso de Historia del País Valenciano, Valencia: Universidad de Valencia, 1981, II, pp. 579-598. 
tarifas impositivas. La universidad valenciana ejercía un estricto control tanto sobre la venta, que podía realizarse, salvo excepciones, sólo en los establecimientos autorizados, como sobre los precios, fijados por el propio consell de la ciudad. J. Broussolle constata en Barcelona la adopción de idénticas medidas por parte de la municipalidad en materia de productos cárnicos ${ }^{10}$. Estas disposiciones facilitaban en gran medida el cobro de los derechos, que eran abonados a los compradores de la imposición directamente por los carniceros en el momento de procederse al peso de las carnes. Las tarifas eran sumamente variables. Las carnes de carneros, ovejas, cabras y terneros abonaban 1 dinero por cada libra de carne además de una deducción de una libra de peso en el momento de efectuarse la venta de las piezas al carnicero. Idénticas tarifas se aplicaban en las ventas de carne de cerdo, fresca o salada, y animales de caza, como ciervos y jabalíes. La carne de buey y de vaca se tasaba a razón de 1 malla y una reducción de 4 libras en el peso. Los terneros de pequeño tamaño se gravaban con 2 sueldos por pieza, mientras que corderos y cabritos pagaban una cantidad menor -2 dineros por pieza- y si su venta se realizaba a peso 1 dinero por libra.

Los animales de matanza para uso doméstico se gravaban asimismo con unas tasas, cuyo control presentaba mayores dificultades. Los derechos no se establecían en relación al peso, como veíamos en las ventas realizadas directamente en carnicerías, sino que las tarifas eran impuestas por piezas. Así, los bueyes y vacas pagaban a razón de 2 sueldos; los terneros, 18 dineros; los carneros, ovejas y cabras, 12 dineros y los cabritos y corderos 2 dineros, mientras que la carne de cerdo era gravada con una tasa de 12 dineros. En el caso de producirse una venta de la totalidad o una parte de estos productos cárnicos, los propios particulares estaban obligados a pagar un suplemento sobre las tasas anteriores.

A diferencia de los cereales y las carnes, únicamente se gravaba el aceite destinado a la exportación, siempre que fuera extraído por vía marítima. En este caso, el propietario debía abonar a los colectores de la imposición una tasa de 1 dinero por cada arroba.

El vino completaba, junto con las carnes, los cereales y el aceite, el conjunto de productos alimenticios gravados en las sucesivas imposiciones decretadas por motivos económicos diversos en las diferentes universidades valencianas, dado que sus rendimientos eran los más elevados y regulares ${ }^{11}$. La primera de las medidas adoptadas se refiere a la disminución de la capacidad del quarter de vino que pasaba de 30 a 28 libras. Al mismo tiempo, las tarifas diferencian claramente las ventas al mayor y al detalle, así como el destinado a uso particular o mercantil con tarifas que oscilan desde los 4 a los 16 dineros por cada libra del precio total.

La imposición de una tarifa sobre los paños, independientemente de la materia

10 J. BROUSSOLLE, "Les impositions municipales de Barcelone de 1328 à 1462 ", Estudios de Historia Moderna, V (1957), p. 44.

11 Idénticas constataciones pueden hacerse para el caso de las universidades catalanas. J. Broussolle, en su estudio sobre las imposiciones decretadas en Barcelona durante el período comprendido entre 1328 y 1472 , las ha clasificado por este motivo dentro del grupo de las denominadas imposiciones permanentes [Les impositions municipales, pp. 33-59]. 
prima utilizada — lana, lino, estopa, cáñamo, algodón, seda - se concretó en la reducción de 1/40 parte de la pieza y en el pago de una tasa de 6 dineros por cada libra del precio de venta.

Finalmente, en las áreas marítimas, especialmente en el Grao de Valencia, se impone una tasa sobre el tráfico de embarcaciones que cubrían los diferentes trayectos comerciales mediterráneos y, en menor medida, atlánticos. Los capítulos establecen una diferenciación en el valor de las tasas en dependencia a la capacidad de las embarcaciones y la distancia respecto a las plazas de procedencia o destino. Las tarifas más elevadas, que oscilaban entre los 1.000 sueldos de máxima y los 300 de mínima, según el navío, correspondían a la ruta del Levante y de Flandes. A continuación, encontramos la zona circunscrita por los puertos nazaries, Cáller, en Cerdeña, la isla de Sicilia, Túnez y Bugía, situados en el sultanato hafsí y los puertos italianos de Venecia, Pisa, Génova y Nápoles. Los derechos abonados se cifran entre un máximo de 400 sueldos y un mínimo de 100. Esta última tasación, en navíos de idéntica capacidad, se aplica asimismo en la ruta magrebí occidental, que comprendía desde Tedelis, en la zona costera zayyaní, hasta Nife, situada en el Marruecos atlántico. Otra de las zonas delimitadas correspondería a la Provenza, a los mercados de Marsella, Aïgues Mortes, Narbona y Colliure con tasas sensiblemente menores, de 23 sueldos, 4 dineros. Finalmente, los trayectos efectuados a lo largo de la costa catalano-balear eran los menos gravados por la imposición: solamente 50 sueldos.

Las diferentes tasas no eran cobradas directamente por los representantes de los diversos estamentos, sino que las imposiciones se vendían por una cantidad preestablecida en subasta pública y era el comprador el encargado de recolectar los derechos correspondientes. Con el objeto de facilitar las ventas y también de evitar posibles fraudes en la recaudación de las sumas obtenidas, se nombraron ocho administradores como representantes de los diferentes estamentos ${ }^{12}$. Para evitar la defraudación se estipuló, asimismo, que la totalidad de los ingresos procedentes de la venta de imposiciones se depositaran en una única taula, al tiempo que se establecía la ilegalidad de realizar ningún pago sin la conformidad de los administradores; los albaranes deberían, en consecuencia, estar refrendados por los sellos de todos y cada uno de los estamentos para que adquirieran validez y pudieran hacerse efectivos. Los poderes otorgados por las Cortes a los administradores son sumamente amplios y no se limitan a las cuestiones referentes a la administración del subsidio. Los capítulos contemplan en este sentido la posibilidad de que ellos mismos tasen en una cantidad fija la cuota de participación en el subsidio de aquellos lugares en que las imposiciones no obtuvieran un precio de venta considerado suficiente, o bien existiera algún tipo de resistencias en el momento de materializar los pagos correspondientes. Estas

12 La elección recayó en Umbert de Tous, de la orden de Montesa, Arnau Bru, rector de la iglesia de San Salvador de Valencia, Jaume Castellar, Gilabert de Noguera, Joan Escrivà, Bartomeu Saranyó, Bonafonat de Vall-llebrera y Pere de Clariana [ACA, C, reg. 1377, f. 63 r.vv. (Valencia. 8, junio, 1340)]. Las tasas debían ser recaudadas en lugares muy distantes entre sí, de manera que se les otorga que puedan nombrar procuradores que desempeñen en su nombre algunas de las tareas [ibídem, f. 64 r.-v. (Valencia. 9, junio, 1340)]. 
prerrogativas se verían refrendadas por la capacidad de los administradores de proceder a la confiscación de bienes, tanto en lugares bajo jurisdicción de la nobleza, laica o eclesiástica, o de la monarquía, en el caso de incumplimiento de los términos acordados sobre el pago del subsidio.

Pero al mismo tiempo, se establecía un férreo control sobre los administradores, quienes deberían rendir cuentas regularmente ante las personas nombradas por las Cortes para este cometido, pero no ante el rey o sus oficiales. Igualmente, se establecía que las cantidades obtenidas a través del subsidio únicamente pudieran ser empleadas en la cuestión de la defensa marítima del estrecho y se prohibía terminantemente que el monarca pudiera disponer directamente de esas sumas.

En definitiva, con estas disposiciones, refrendadas en su totalidad por Pedro el Ceremonioso como condicionante indispensable para la obtención del subsidio, las Cortes se aseguraban un control total y absoluto tanto de la tasación como de la administración del subsidio e impedian cualquier posible injerencia de la monarquía.

A cambio de esta ayuda pecuniaria, el monarca catalano-aragonés no podría exigir ninguna otra exacción mientras durase la recaudación de las cantidades concedidas $^{13}$, al tiempo que confirmaba a perpetuidad los privilegios e inmunidades de los diferentes estamentos ${ }^{14}$.

Tras la conformidad mostrada en las Cortes sobre la concesión del subsidio para la guerra de Marruecos, Pedro el Ceremonioso otorga a los administradores nombrados para la leva de la almoina plenas facultades para recibir las firmas que refrendaban la concesión. De esta manera podía regresar inmediatamente a Cataluña, donde esperaba recibir, al igual que en el reino de Valencia, ayuda monetaria para proceder al armamento de galeras. Ciertas dilaciones en el momento de procurar algunas firmas, como la de Lope de Luna, señor de la ciudad de Segorb, o la del obispo de Tortosa, a pesar de sus intenciones claramente favorables a la imposición de la tasa, significaban importantes retrasos en la recaudación del subsidio ${ }^{15}$. Otros señores, laicos y eclesiásticos, ofrecieron asimismo algunas resistencias en el momento de suscribir los acuerdos tomados en las Cortes viéndose por ello amenazados con la con-

13 Así lo certifica Pedro el Ceremonioso en las cartas dirigidas a la universidad de Valencia [ACA, C, reg. 1377, f. 66 r.-v. (Valencia. 5, junio, 1340)]; a Pere, conde de Ribagorza y Ampurias [ibídem, f. 72 r. (Barcelona. 15, julio, 1340)]; a Teresa de Entenza, viuda de Juan Eiximen de Urrea, Toda Pérez de Urrea, viuda de Artal de Alagón, hija y heredera de Juan Eiximen y de Teresa, y a Juan Eiximen de Urrea, hijo de Artal de Alagón y de Toda Pérez [ibidem, f. 80 r.-v. (Barcelona. 4, agosto, 1340)]; a Lope de Luna, señor de la ciudad de Segorb [ibídem, ff. 95 v.-96 r. (Barcelona. 25, agosto, 1340)]; a Pere, señor de Xèrica, a Pere de Tous, maestre de la orden de Montesa, a Berenguer, obispo de Tortosa, $y$, en general, a las universidades y a los señores laicos y eclesiásticos con posesiones en el reino de Valencia [ibídem, ff. 88 v.-89 r. (Barcelona. 30, agosto, 1340)].

14 ACA, C, reg. 1377, f. 111 r.-v. (Barcelona. 1, octubre, 1340),

15 La firma no se efectuaría hasta finales del mes de julio [ACA, C, reg. 1377, f. 63 r.-v. (Valencia. 8, junio, 1340); ibídem, f. 64 r. (Valencia. 9, junio, 1340); ibídem, f. 69 r.-v. (Barcelona. 7, julio, 1340); ibidem, f. 69 v. (Barcelona. 7, julio, 1340)]. 
fiscación de sus bienes ${ }^{16}$. Las amplias facultades otorgadas a los administradores sobre la posibilidad de efectuar ventas, arrestos y confiscaciones paliaron parcialmente las resistencias mostradas en determinados lugares para la colecta de las sumas correspondientes ${ }^{17}$; unas resistencias especialmente marcadas en los territorios del reino de Valencia ultra Sexonam, donde se vieron obligadas a intervenir las propias autoridades reales ${ }^{18}$.

La pronta expedición de una flota de cuatro galeras y un leño prevista para finales de septiembre y a la que estaban destinados los beneficios inmediatos de la almoina, obligó a proceder con cierta rapidez a los administradores. No se consiguieron las cantidades necesarias en el tiempo preciso, de manera que el monarca tuvo que recurrir a los préstamos particulares para poder cumplir con los plazos establecidos ${ }^{19}$.

La inexistencia de una pronta solución al conflicto bélico con Marruecos y la continuidad de los envíos de galeras al área del Estrecho determinó la necesidad inmediata de una nueva subvención monetaria, decretada en las Cortes celebradas en Valencia en diciembre de 1342, y con una duración de otros tres años. En ese momento particular, los intereses prioritarios de Pedro el Ceremonioso se centraban no tanto en la guerra de Marruecos como en la recuperación de los dominios del rey de Mallorca y en su anexión a la Corona. De hecho, consigue que en el donativo otorgado por las Cortes se incluya una cláusula conforme, en el caso de que fuera necesario, pudiera utilizar una parte de esa cantidad en los preparativos del desembarco en Mallorca, programado para efectuarse en los meses siguientes. La condición requerida era procurar previamente una suma suficiente para armar las diez galeras que deberían cubrir la vigilancia en los mares de Tarifa; el resto podría ser utilizado en la

16 Es el caso de Eiximen de Tovia, señor de Xella, quien es requerido en numerosas ocasiones por Pedro el Ceremonioso para que se adhiera al acuerdo [ACA, C, reg. 1377, f. 89 v. (Barcelona. 31, agosto, 1340); ibidem, f. 89 v.-90 r. (Barcelona. 31, agosto, 1340); ibídem, f. 90 r. (Barcelona. 31, agosto, 1340$)$.

17 ACA, C, reg. 1377, ff. 63 v.-64 r. (Valencia. 9, junio, 1340); ibídem, f. 64 r. (Valencia. 9, junio, 1340).

18 ACA, C, reg. 1377, f. 131 v. (Barcelona. 25, noviembre, 1340); ibídem, f. 132 r. (Barcelona. 15 , noviembre, 1340). Sin duda, los problemas más graves se produjeron por la negativa de Eleonora, viuda de Alfonso el Benigno y madrastra de Pedro el Ceremonioso, de proceder al pago de la suma correspondiente por sus posesiones en los territorios de Valencia ultra Sexona, una suma que ascendía a 30.000 sueldos anuales y que le fue requerida en numerosas ocasiones, llegándose incluso a amenazarla con la confiscación de sus bienes [ACA, C, reg. 1378, f. 92 v. (Barcelona. 1, mayo, 1342); ibídem, ff. 92 v.-93 r. (Barcelona. 1, mayo, 1342); ibidem, f. 106 r. (Barcelona. 5, julio, 1342); ibídem, f. 107 v. (Barcelona. 26, julio, 1342)]. La causa final de esta negativa no era tanto una marcada oposición a la política del monarca como una cuestión de enfrentamientos personales ya desde la época de Alfonso el Benigno.

19 El conde de Prades, Ramón Berenguer, adelantó por este motivo la suma de 15.000 libras barcelonesas [ACA, C, reg. 1378, ff. 23 v.-24 r. (Valencia. 1, marzo, 1341)]. La duración del conflicto con Marruecos y los sucesivos armamentos impidieron obtener un sobrante suficiente para proceder a la devolución de ese préstamo, más los intereses generađos, en los términos previstos inicialmente y a posponer el pago de la deuda [ibídem, f. 69 v. (Valencia. 30, octubre, 1341); publ. P. DE BOFARULL, Codoin, VII, doc. 37 , p. 152)]. 
ejecución contra el soberano mallorquín ${ }^{20}$. De hecho, la colaboración de algunos nobles y los servicios prestados por éstos y sus huestes en el viaje a Mallorca, en junio de 1343, les eximió del pago adeudado por razón de la almoina; exenciones que iban en detrimento de las sumas dedicadas a la defensa marítima del Estrecho ${ }^{21}$. En los capítulos acordados en Cortes se establecía asimismo que en el momento que finalizara la cuestión mallorquina, las cantidades obtenidas a través de la imposición de la almoina deberían ser invertidas de nuevo en su totalidad en el objetivo primero al que estaba destinada la ayuda, es decir, a la guerra de Marruecos ${ }^{22}$.

La insuficiencia de numerario para sufragar los gastos derivados de ambos conflictos militares obligó al monarca a pedir subsidios extraordinarios. Así, en noviembre de 1343 , los jurados y prohombres de la ciudad de Valencia concedieron al rey una cantidad suplementaria a pagar en períodos cuatrimestrales durante dos años. Las sumas, al igual que las anteriores, se obtendrían a través de las imposiciones decretadas en la ciudad y sus términos jurisdiccionales ${ }^{23}$. Los productos gravados, al igual que observábamos en los capítulos otorgados por las Cortes de 1340, son los alimenticios - cereales, vino y carnes-, la producción textil y el tránsito de embarcaciones comerciales; pero, en este caso específico de la ciudad de Valencia, se incluyen, asimismo, diversas tasas que gravan la exportación de una serie de mercancías, como los cueros, las especias, la plata y la cera ${ }^{24}$.

En general, se observa una fuerte reducción de las tasas impuestas sobre los cereales respecto a las imposiciones decretadas en 1340 para la totalidad del territorio valenciano. Así, el trigo candeal pasa de gravar 24 dineros por cahíz a únicamente 6 dineros; los derechos sobre el resto de los cereales — panizo, maíz y cebada - disminuyen en idéntica proporción: 3 dineros por cahíz frente a los 12 de 1340, es decir, el importe de las tasas disminuye en un porcentaje que oscila en torno al $75 \%$. El consejo de la universidad alude a la gran carestía que sufría el reino de Valencia ese año como una de las causas justificantes de la disminución en la cuantía de la ayu$\mathrm{da}^{25}$. Idénticas características se constatan en las imposiciones sobre el tráfico de

20 ACA, C, reg. 1378, f. 121 r.-v. (Valencia. 3, enero, 1343).

21 En octubre de 1343, tras haber anexionado nuevamente las Baleares a la Corona, Pedro el Ceremonioso ordena que le sean perdonadas a Pere, señor de Xèrica, las 2.398 libras de moneda real valenciana que adeudaba a los administradores de la elemosine. No es un caso único. A Gonçalvo García, señor de Jumella, Xinosa, Motnover, la Daja y Xacarella, se le exime del pago de 3.720 sueldos que debían sus vasallos por estos lugares. Las razones argumentadas responden a la importante ayuda prestada al monarca durante la toma de la isla por éstos y otros nobles con posesiones en el reino de Valencia [ACA, C, reg. 1378, f. 136 r.-v. (Valencia. 21, octubre, 1343); ibidem, ff. 137 r.-138 r. (Valencia. 27, octubre, 1343); ibídem, f. 138 r. (Valencia. 27, octubre, 1343)].

22 ACA, C, reg. 1378, ff. 126 r.-127 r. (Barcelona. 24, marzo, 1343).

23 ACA, C, reg. 1378, ff. 142 v. -143 r. (Valencia. 17, noviembre, 1343).

24 Los capítulos de estas imposiciones, con fecha del 5 de noviembre de 1343 se encuentran en el registro 875 de la sección de Cancillería del Archivo de la Corona de Aragón, folios 194 r.-196 v.

25 Esta misma alegación es utilizada por Pedro el Ceremonioso para denegar las sucesivas peticiones de cereales elevadas por el rey de Castilla destinadas al aprovisionamiento de las tropas ocupadas en el sitio de Algeciras. 
embarcaciones, donde se observa la misma reducción de las tasas del orden de las $3 /$ 4 partes. Las tarifas sobre las carnes y el vino muestran alguna pequeña variación, pero en general denotan una estabilidad respecto a las tasas anteriores. La imposición sobre la producción textil es la única que sufre un aumento bastante considerable: de los 6 dineros impuestos en 1340 por cada libra del precio de las piezas, pasa a gravarse con una tasa de 8 dineros. Es importante resaltar, en primer lugar, el marcado carácter proteccionista de estos capítulos respecto a la comercialización de paños autóctonos y de producción extranjera en la plaza de Valencia. Sólo las operaciones de compra-venta de piezas de lino, estopa, cáñamo o seda realizadas a ús de vestir, estaban sujetas al pago de derechos; por el contrario, las efectuadas a ús de mercaderia no abonaban las tarifas correspondientes.

A diferencia de las ordenaciones de 1340, los capítulos aprobados por la universidad valenciana incluían, dentro de los productos sujetos a un determinado gravamen, algunas mercancías destinadas a la exportación. Los cueros y las especias abonaban 4 dineros por libra; la tasa impuesta sobre la cera era de menor cuantía: 3 dineros por libra. Es de suponer que las imposiciones sobre estos productos debían ser notablemente rentables dada la creciente actividad mercantil mostrada por la plaza valenciana a lo largo del trescientos. En la ciudad de Valencia convergían las materias primas y los productos manufacturados procedentes de las zonas rurales que limitan con los territorios de la urbe, pero también de las demás áreas de producción peninsulares y del comercio internacional. La plaza valenciana extendía su radio de influencia hacia el interior, hacia Castilla, mientras que las embarcaciones que entraban y salían del Grao se movían a pequeña escala entre Provenza, Baleares y el litoral catalán, valenciano y castellano meridional o en dirección a las costas del Magreb y del reino nazarí, y a larga distancia con los centros comerciales del Mediterráneo oriental. La producción local abastecía en parte las exportaciones de cueros, cera y especias, aunque en gran medida procedían de la reexportación de los cargamentos procedentes de las diferentes áreas en contacto comercial con la plaza valenciana.

En este contexto de intensa actividad mercantil se justifica la rentabilidad de una imposición, que ascendía a 3 dineros por libra, sobre la extracción de la plata, cuya exportación se veía favorecida por el déficit de ciertas operaciones comerciales en determinadas áreas, especialmente del Levante mediterráneo.

Además de la ciudad de Valencia otras comunidades reales concedieron subsidios de diferente cuantía. En total, una suma de 260.000 sueldos, obtenidos igualmente por vía de imposiciones sobre los cereales, el vino las carnes y otras mercancías, repartidas de manera proporcional entre las diferentes universidades ${ }^{26}$.

La totalidad del subsidio, al igual que se estipulaba en los capítulos redactados por la universidad valenciana, sería sufragado en un período de dos años, en pagos

26 Contribuciones de las comunidades reales valencianas a la Guerra del Estrecho: Morella, $78.923 \mathrm{s.}$.; Castalla/Favanella, 972 s. 2 dn.; Játiva, 64.366 s.; Morvedre, 54.237 s. 7 dn.; Alzira, 27.423 s. 5 dn.; Burriana, 13.180 s. 8 dn.; Cullera, 7.403 s.; Castellfabib, 4.021 s. 11 dn.; Alpont, 3.888 s. 9 dn.; Ademuç, 2.448 s. 5 dn.; Penàguila, 1.620 s. 3 dn.; Jijona, 1.529 s. 11 dn. 
cuatrimestrales depositados en la taula de Bernat Joan, en la ciudad de Valencia. Como contraprestación, el monarca se compromete a no exigir durante esos dos años ninguna otra subvención, questia o peita extraordinaria, ni la convocatoria de un ejército con motivo de la ejecución contra el Rosellón y la Cerdaña. Además, en el caso de que antes de los proyectados dos años finalizara este conflicto y la guerra de Marruecos, las cantidades procedentes del subsidio los emplearía en la redención y luición de los castillos, lugares y jurisdicciones alienados en el reino de Valencia desde el inicio del conflicto con el rey de Mallorca.

Estas subvenciones no bastaron para sufragar los enormes gastos derivados de los conflictos bélicos que se desarrollaban simultáneamente en el Estrecho y el Rosellón y Pedro el Ceremonioso se vio en la obligación de recurrir a nuevas peticiones de subsidio, siempre a cambio de ciertas prerrogativas. En febrero de 1344 Pere de Tous, maestre de la orden de Montesa, otorgaba al monarca una subvención de 60.000 sueldos en idénticas condiciones a las decretadas por las universidades anteriores, es decir, en pagos efectuados cada cuatro meses durante un espacio temporal de dos años, y tomando como base los mismos capítulos sobre las imposiciones aprobados en la ciudad de Valencia y las villas reales ${ }^{27}$. La concesión de un privilegio real otorgado por Pedro el Ceremonioso, a cambio de la ayuda monetaria, respecto a la extracción de lana sin licencia de los oficiales reales, justificaría la generosa donación ${ }^{28}$.

Finalmente, la firma de una tregua en marzo de ese mismo año, y la suscripción del tratado por la Corona de Aragón en 1345, daba por finalizado un conflicto que tuvo como consecuencia más evidente el final de la intervención mariní en la península ibérica.

27 ACA, C, reg. 876, f. 33 r.-v. (Barcelona. 5, marzo, 1344); ibidem, reg. 1378, f. 151 v. (Barcelona. 21, marzo, 1344).

28 ACA, C, reg. 876, f. 33 v. (Barcelona. 11, marzo, 1344). La orden de Montesa poseía amplios dominios, dentro del reino de Valencia, en la zona del Maestrazgo, una de las áreas de producción lanera más importantes de la península y donde se aprovisionaban algunas compañías catalano-aragonesas y, sobre todo, italianas. Lugares como San Mateu, Peñíscola, Salzadella, Albocàsser, Onda, Tirig o Adzaneta, entre otros, todos ellos pertenecientes a la orden, figuran entre los principales centros productores identificados por F. Melis, tomando como base los datos procedentes de la documentación del Archivo Datini de Prato, de donde se deriva la importancia económica para la orden de Montesa de esta prerrogativa real [F. MELIS, «La llana de l'Espanya mediterrànea i de la Berberia occidental en els segles XIV-XV”, en València, un mercat medieval, A. FURIÓ (ed.), Valencia: Diputación Provincial de Valencia, 1985, pp. 75-80]. 